\title{
SIMULAÇÃO DO COMPORTAMENTO DA TEMPERATURA DO SOLO ATRAVÉS DA TEMPERATURA DO AR
}

\author{
${ }^{1}$ Julio Sena; ${ }^{1}$ Maria E. Pinheiro; ${ }^{1}$ Daniele Aimi; ${ }^{1}$ Cláudio Teichrieb; ${ }^{1}$ Patrícia Feldhaus; \\ ${ }^{1}$ Pablo Oliveira; ${ }^{1}$ Hans Zimermann; Débora Roberti.
}

\author{
${ }^{1}$ Universidade Federal de Santa Maria
}

juliosena45@gmail.com

RESUMO: A partir de dados observacionais de temperatura do solo e do ar, é obtida uma equação para descrever a temperatura do solo a $5 \mathrm{~cm}$ de profundidade em função da temperatura do ar para uma região de cultivo de arroz irrigado. A região do estudo apresenta períodos de alagamento. A equação obtida descreve de forma satisfatório os períodos secos.

PALAVRAS-CHAVE: temperatura do solo, temperatura do ar.

\section{INTRODUÇÃO}

Uma importante variável para o sucesso de uma safra agrícola é a temperatura do solo, pois a decomposição de microorganismos e processos de reações químicas que ocorrem no solo são diretamente influenciados pela temperatura (Ahmad \& Hasul, 2008). Desse modo, estudar a temperatura do solo é de grande importância para regiões de cultivo. Stenmetz et al (2009), por exemplo, estudaram as temperaturas favoráveis à semeadura do arroz em 8 sítios experimentais de culturas irrigadas no Rio Grande do Sul.

Nestas regiões, a temperatura do solo favorável ao cultivo foi de aproximadamente $20^{\circ} \mathrm{C}$ para 7 das regiões no terceiro decênio de setembro e, após o terceiro decênio de outubro, o cultivo é favorável em todo o estado gaúcho com exceção de Caxias do Sul. Em outro estudo, de Lima e Galvani (2012) analisaram o comportamento da temperatura do solo e do ar em uma região de manguezal localizada no litoral de São Paulo. Entre seus resultados, eles encontraram que as maiores diferenças de temperatura entre o solo e o ar ocorrem nos 
meses de junho e dezembro, com valores de $1,36{ }^{\circ} \mathrm{C}$ e $1,35^{\circ} \mathrm{C}$ respectivamente. Por outro lado, a menor diferença encontrada por eles foi de $0,29^{\circ} \mathrm{C}$ no mês de fevereiro.

Tendo como base a importância de informações a respeito da temperatura do solo, propõese, neste trabalho, investigar um meio de simular o comportamento da temperatura do solo apenas com dados de temperatura do ar. Estimar a temperatura do solo através da temperatura do ar pode minimizar custos experimentais e trabalhos (Ahmad e Hasul, 2008).

\section{MATERIAIS E MÉTODOS}

O sítio experimental utilizado nesse estudo é uma região de cultivo de arroz irrigado, localizada em Paraíso do Sul, RS, Brasil. O sítio experimental compreende uma área de aproximadamente $1,25 \mathrm{~h}$, sendo caracterizado como plana e homogênea. A temperatura do solo foi medida a $5 \mathrm{~cm}$ de profundidade, com o sensor STP01 Soil Temperature Profile e a temperatura do ar foi medida a $10 \mathrm{~m}$ de altura com um sensor de temperatura e umidade HMP-45.

O ajuste linear entre a temperatura do solo e a temperatura do ar foi obtida com um mês de dados de 2003 (dias julianos de 218 a 248) considerado como período I.

O próximo passo foi utilizar a equação obtida para simular o comportamento da temperatura do solo no mês de janeiro de 2004 (período II) e também para o período que vai do dia juliano 130 ao 160 de 2004, entre os meses de maio e junho (período III). O período II apresenta uma lamina de água sobre o solo, ou seja, o solo está alagado e com plantação de arroz.

\section{RESULTADOS E DISCUSSÃO}

O comportamento da temperatura do solo em função da temperatura do ar, mostrado na Figura 1 . $\mathrm{O} \mathrm{R}^{2}$, foi de 0.81 , demonstrando a boa correlação entre os dados de temperatura do ar e do solo. A equação que descreve a temperatura a $5 \mathrm{~cm}\left(\mathrm{~T}_{5}\right)$ de profundidade em função da temperatura do ar $\left(\mathrm{T}_{\mathrm{ar}}\right)$ é:

$$
\mathrm{T}_{5}=0.6 \mathrm{~T}_{\mathrm{ar}}+7.4
$$




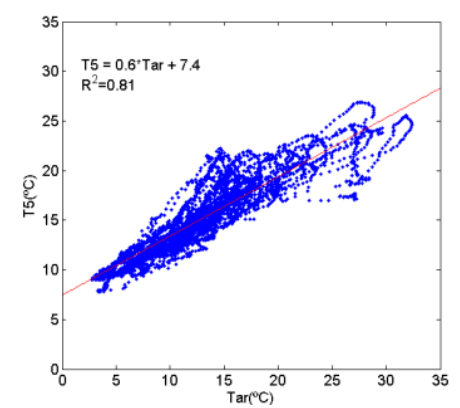

Figura 1 - Diagrama de espalhamento para a temperatura do solo a $5 \mathrm{~cm}$ de profundidade em função da temperatura do ar, correspondente ao período I.

As figuras 2 e 3 mostram o comportamento da temperatura do solo observada a $-5 \mathrm{~cm}(\mathrm{t} 5)$ e a temperaturas estimadas (t5e) nos períodos II e III pela equação (1), respectivamente. Na figura 2, nota-se uma pequena defasagem entre os gráficos e uma diferença estimada em aproximadamente $7^{\circ} \mathrm{C}$ entre os valores observados e simulados. Esta defasagem pode ser explicada pelo fato de que a equação de ajuste foi obtida num período seco e os dados simulação são para um período alagado. Por outro lado , quando se simula a temperatura do solo para um período do ano também seco (Figura 3), nota-se que a equação (1) simula a temperatura do solo de forma satisfatória.

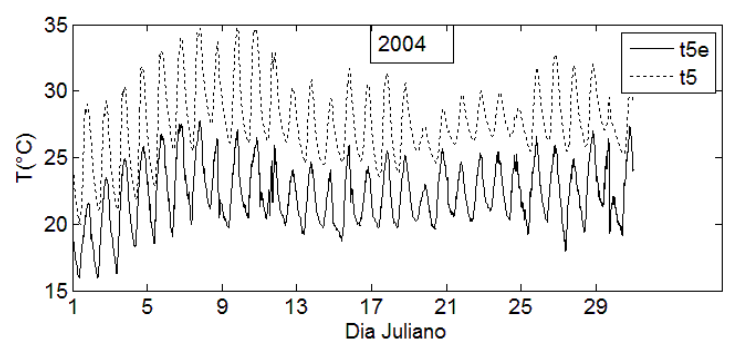

Figura 2 - Temperatura do solo observada a - $5 \mathrm{~cm}(\mathrm{t5})$ e temperatura estimada (t5e), referente ao período II.

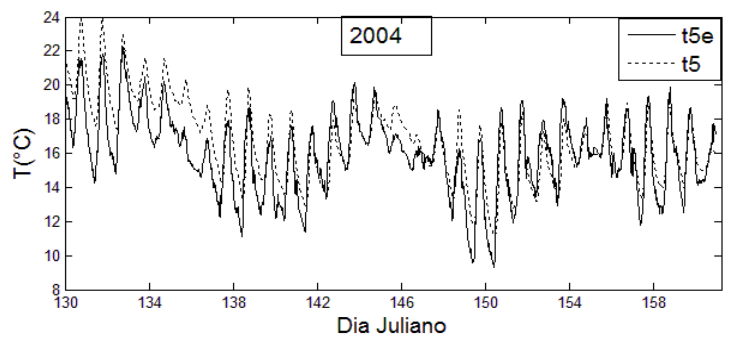


Figura 3 - Temperatura real do solo a $-5 \mathrm{~cm}$ (t5) e temeperatura estimada (t5e), referentes ao período III.

\section{CONCLUSÃO}

A temperatura do solo pode ser obtida através da temperatura do ar para regiões de cultivo de arroz irrigado, mas não se pode utilizar a mesma equação para períodos irrigados ou secos.

\section{BIBLIOGRAFIA}

Steinmetz S. et al.. Temperatura do solo favorável para o início da semeadura do arroz irrigado no Estado do Rio Grande do Sul Pesquisa Agropecuária gaúcha. Porto Alegre, n. 02 v. 15 , p. $99-104,2009$.

Lima \& Galvani. Análise Da Temperatura Do Solo E Do Ar No Manguezal Do Litoral Sul Do Estado De São Paulo. RevistaFigure 1: Profiles of potential temperature (left) and specific humidity (right) for forest (top) and pasture (bottom) sites during the day Geonorte. n. 2, v. 2, p. 1256 - 1266, 2012.

Ahmad F. \& Rasul G. Prediction of soil temperature by air. Temperature; a case study for faisalabad. Pakistan Journal of Meteorology. Pakistan, n. 5, v. 9, p. 19 - 27, july. 2008. 